\title{
THE EFFECT OF ADRENOCORTICOTROPHIC HORMONE ON CHILDREN WITH THE NEPHROTIC SYNDROME. II. PHYSIOLOGIC OBSERVATIONS ON DISCRETE KIDNEY FUNCTIONS AND PLASMA VOLUME ${ }^{1}$
}

BY HENRY L. BARNETT, CAROLYN W. FORMAN, ${ }^{2}$ HELEN MCNAMARA, AND WALLACE W. MCCRORY ${ }^{3}$ (From The New York Hospital and the Department of Pediatrics, Cornell University Medical
College, New York City)

AND

By MILTON RAPOPORT, ALEXANDER J. MICHIE, AND GUILIO BARBERO

(From The Children's Hospital of Philadelphia and the Department of Pediatrics, and Harrison Department of Surgical Research, School of Medicine, University of Pennsylvania, Philadelphia)

(Submitted for publication September 12, 1950 ; accepted, December 4, 1950)

\section{INTRODUCTION}

Inability to predict the time of occurrence of spontaneous diureses in the nephrotic syndrome has retarded investigations of the physiologic changes which may precede, accompany, and follow these heartening but enigmatic events. It has been demonstrated recently that several agents (1-5) are capable of inducing diureses at a predictable time in a far higher percentage of trials than could be attributed to chance. Adrenocorticotrophic hormone (ACTH) is one such agent, and the abrupt, profuse, and sustained diureses which may accompany or follow its administration are clinically similar to the dramatic diureses which occur spontaneously. Clinical observations on the effect of $\mathrm{ACTH}^{4}$ on a group of children with the nephrotic syndrome is the subject of a separate report (6) in which the possible clinical significance of the results is also discussed. Serial physiologic measurements were made on selected patients before, during, and after administration of ACTH. These observations were directed toward an increased understanding of the syndrome itself and especially of the mechanism of diuresis rather than

\footnotetext{
1 Presented in part before the Society of Pediatric Research at French Lick; Indiana, on May 9, 1950.

2 Public Health Service Postdoctorate Fellow, 1949-51.

3 Lewis Cass Ledyard, Jr. Fellow in Pediatrics, 1949-50. Present address: Children's Hospital of Philadelphia.

4 We wish to thank Dr. John R. Mote of the Armour Laboratories for allocating the ACTH used in these observations.
}

toward evaluation of possible relationships between the disease and pituitary or adrenocortical function. As an integral part of the approach, an attempt was made to disclose, if possible, consistent changes which might precede the outset of diuresis and, to this end, as many relevant physiologic measurements as practicable were made. These included: blood volume; discrete kidney functions; concentrations of electrolytes and nitrogenous constituents of serum; metabolic balances of electrolytes and nitrogen; serum lipid fractions; and urinary protein and sediment.

It has not been possible from any one or combination of changes to predict when diuresis would occur in relation to administration of ACTH. The most striking changes observed after the outset of diuresis were increases in plasma volume and unexpectedly large increases in glomerular filtration rate (GFR). These changes together with observations on other discrete kidney functions are described in the present paper. Observations on other measurements will be the subject of a subsequent report (7).

\section{SUBJECTS AND METHODS}

Observations were made on eight children with the nephrotic syndrome whose clinical status and course during ACTH administration is described in a separate report (6). Clinical data relevant to the observations presented here are included in Table $I$.

Various combinations of the following measurements 
were made before, during, and after administration of ACTH : daily weight; plasma volume and hematocrit; clearances of inulin $\left(C_{1 N}\right)$; endogenous creatinine $\left(C_{C R}\right)$; thiosulfate $\left(\mathrm{C}_{\mathrm{THIO}}\right)$ and $\mathrm{p}$-aminohippurate $\left(\mathrm{C}_{\mathrm{PAB}}\right)$; and maximum tubular excretion of PAH $\left(\mathrm{T}_{\mathbf{M}_{\mathbf{P A B}}}\right)$. In three children (I. C., K. N., J. S.), 24-hour clearances of endogenous creatinine $\left(\mathrm{C}_{\mathrm{Cr}-24}\right)$ were measured. These children were on low salt (20 meq. per day) but otherwise normal diets. Most of the time they were ambulatory and normally active.

Methods for inulin, p-aminohippurate, urea (8) and endogenous creatinine (9), in blood and urine, and the catheterization and infusion technic used for short-term simultaneous clearances have been described (8). Serum and urine thiosulfate concentrations were determined by the method of Newman, Gilman, and Phillips (10). $\mathrm{C}_{\mathrm{CR}-2 \mathrm{~A}}$ was calculated using 24-hour creatinine excretion and mid-point serum values interpolated from creatinine determinations made one to three days apart. Plasma volume was measured with T-1824 using a single 10minute blood sample and the acetone extraction method of Chinard and Eder (11) for lipemic sera. Blood volume was calculated from plasma volume and hematocrit (12).

\section{RESULTS ${ }^{5}$}

Changes observed in discrete kidney functions and plasma volume in relation to hormone administration are given in Table I. Data from B. B. and I. C. are shown graphically in Figures 1 and 2.

\section{Glomerular filtration rate}

The most striking changes observed during or following diureses associated with ACTH administration were marked increases in $\mathrm{C}_{\mathrm{IN}}$. Such increases were observed on eight occasions in six of the eight children and were greatest in patients with low initial values. Thus increases in $\mathrm{C}_{\text {IN }}$ of $179,211,190,50$, and $256 \%$ above control values were observed respectively in I. C., K. N., B. B., M. L., and S. S. ${ }^{\circ}$ In B. B., this change in $\mathrm{C}_{\mathrm{in}}$ represents an increase from 35 to $133 \%$ of normal (Figure 1). In the three children whose initial values were within the normal range, measure-

5 The frequency with which diuresis has been observed with ACTH in children with the nephrotic syndrome is reported separately (6). In this group of eight children, selected because measurements had been made both before and after ACTH, a diuresis failed to occur in only one of 14 courses. This failure occurred when only $50 \mathrm{mg}$. per day for three and one half days was given to a child (I. C.) who diuresed on three other occasions with larger dosages.

Only a small fraction of the observed increases in $C_{1 x}$ could be related to increases in rate of urine flow during diuresis.

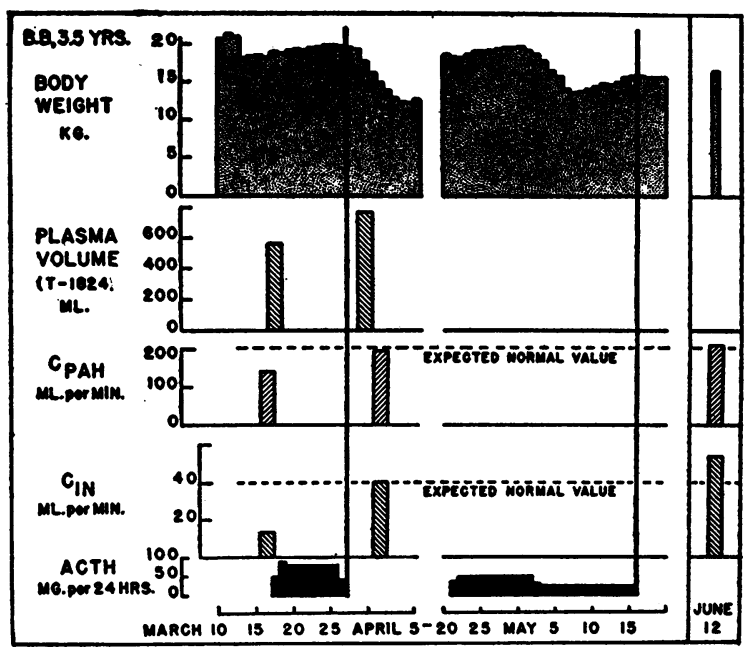

Fig. 1. Relation of Changes in Body Weight, Plasma Volume, and Clearances of Inulin and P-Aminohippurate to Administration of ACTH in a Child with the Nephrotic Syndrome

ments of $\mathrm{C}_{\mathrm{in}}$ showed no significant increase in two (J. S. and R. T.), but revealed an increase to the high value of $123 \%$ of normal in one (R. K.). Failure to observe an increase in $\mathrm{C}_{\mathrm{IN}}$ following diuresis (as in I. C., February 1) may possibly be due to failure to make the measurement at the proper time as discussed later.

In an attempt to determine when changes in GFR occurred and to follow their course, 24-hour clearances of endogenous creatinine were measured. The ratio of $C_{C R}: C_{I N}$ is irregularly greater than one in children with kidney disease (17). Consequently, repeated short term measurements of this ratio were made to relate changes in the 24 hour clearance to changes in GFR. Even though changes in this ratio were taken into account, $\mathrm{C}_{\mathrm{CR}-24}$ was interpreted only as reflecting changes in rather than as an absolute measure of GFR. Despite these reservations, changes in $\mathrm{C}_{\mathrm{CR}-24}$ were sufficiently large to demonstrate that GFR increased during the first 24 hours of diuresis, as shown in Figure 2. Additional impressions concerning changes in GFR during and following ACTH administration are gained from inspection of the data from I. C.?

7 In this patient and in others receiving cortisone in larger dosages no diuresis occurred and no increase in GFR was observed. On the contrary, a marked fall in GFR was observed in S. S. 15 days after he had received $100 \mathrm{mg}$. of cortisone in seven days. There are not sufficient data to indicate the significance of this observation. 


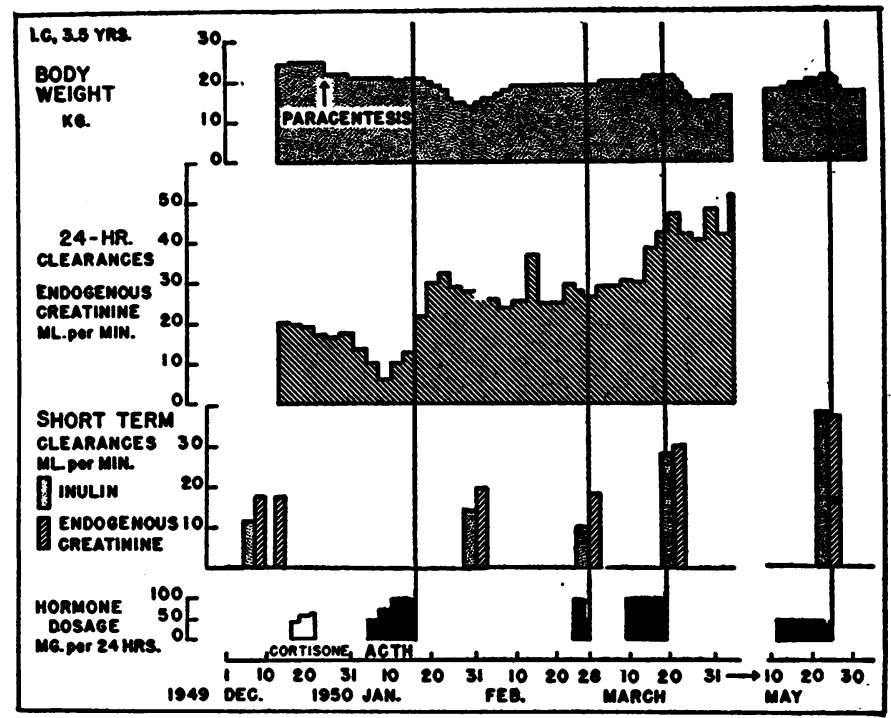

Fig. 2. Relation of Changes in Body Weight and Clearances of Inulin and Endogenous Creatinine to Administration of ACTH in a Child with the Nephrotic Syndrome

The decrease in $\mathrm{C}_{\mathrm{CR}-24}$ seen during the first course of ACTH administration (January 4 to 16) has been observed in other patients and was often associated with a marked rise in serum urea nitrogen and endogenous creatinine. These changes suggest a temporary fall in GFR during ACTH administration. The low value for $\mathrm{C}_{\mathrm{IN}}$ measured on February 28, one day after a three day course of ACTH which did not induce diuresis, lends support to this impression. ${ }^{8}$ The pattern of changes in $\mathrm{C}_{\mathrm{CR}-24}$ in Figure 2 suggests that each diuresis was accompanied by an increase in GFR and followed by a decrease from the maximum value with subsequent stabilization at a value slightly or markedly above the control. It is possible that the fall in GFR may already have occurred when $C_{\text {IN }}$ was measured on February 1, 1950, since re-accumulation of edema already had begun. Repeated responses to ACTH may, however, be as-

\footnotetext{
$8 \mathrm{C}_{\mathrm{CR}}$, measured simultaneously with $\mathrm{C}_{\mathrm{IN}}$, showed a comparable decrease at this time. Failure of $\mathrm{C}_{\mathrm{CR}-\mathrm{s}}$ to reflect this decrease may be partly explained by the inaccuracy of calculating clearances using mid-point values for serum creatinine concentrations interpolated from determinations made on fasting samples taken at intervals of several days (18). $\mathrm{C}_{\mathrm{CR}-24}$ was consistently higher than $C_{\text {Cn }}$ which might be expected from the fact that the latter was always measured early in the day with the subject at rest and in a fasting state, whereas the former might be affected by such factors as eating and activity.
}

sociated, as shown in Figures 1 and 2, with a progressive increase in GFR to normal (I. C.) or even "supernormal" values (B. B.).

Changes of this order of magnitude in $\mathrm{C}_{\mathrm{IN}}$ in children with diseased kidneys must raise the question of the validity of $C_{I N}$ as a measure of GFR under these conditions. This question becomes especially pertinent in view of the consistent changes observed in three children (I. C., K. N., and B. B.) in the $C_{C R}: C_{I N}$ ratio which decreased from a range of 1.5 to 1.9 before to a range of 1.0 to 1.4 after diuresis. However, the reasonably good agreement between $\mathrm{C}_{\mathrm{IN}}$ and $\mathrm{C}_{\mathrm{THIO}}\left(\mathrm{C}_{\mathrm{THIO}}\right.$ : $\mathrm{C}_{\mathrm{IN}}$ ratios ranging from 0.9 to 1.2 ) at both decreased and increased values of $C_{\text {IN }}$ provides evidence that $\mathrm{C}_{\mathrm{IN}}$ was a measure of GFR in these children. The changes observed in the $C_{C R}: C_{I N}$ ratio are unexplained at present.

\section{Effective renal plasma flow $\left(C_{P A B}\right)$}

Significant and consistent increases in $\mathrm{C}_{\mathbf{P A B}}$ were observed to accompany increases in $\mathrm{C}_{\mathrm{IN}}$ during diureses occurring with ACTH. However, increases in $\mathrm{C}_{\mathbf{P A H}}$ were consistently less than those in $\mathrm{C}_{\mathrm{IN}}$ so that in the six children (I. C., K. N., B. B., R. K., M. L., and S. S.) who showed an increase in $C_{I N}$ the $C_{I N}: C_{P A B}$ ratio increased from a range of 0.10 to 0.17 before to a range of 0.22 to 0.32 after diuresis. Whether these changes 


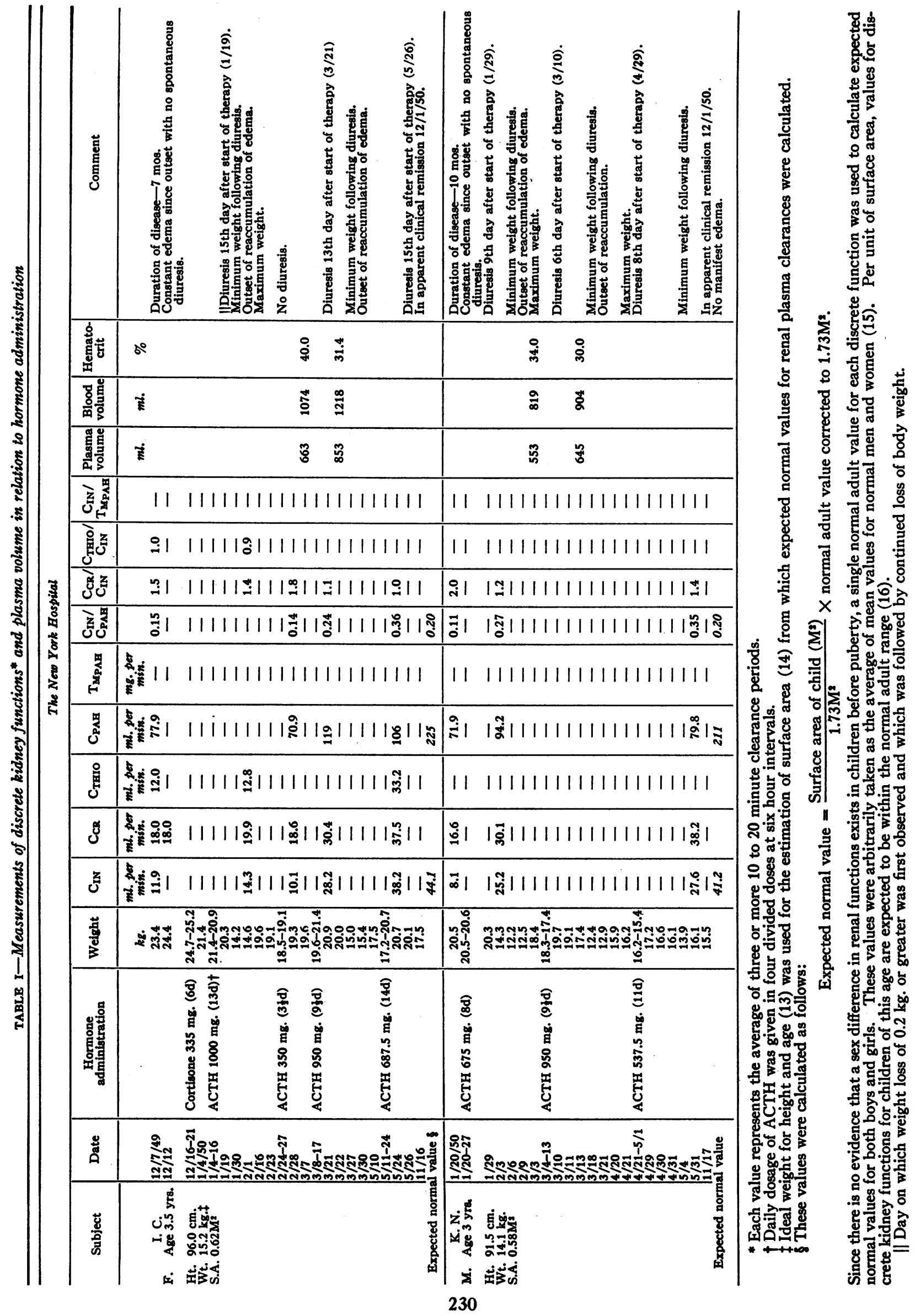




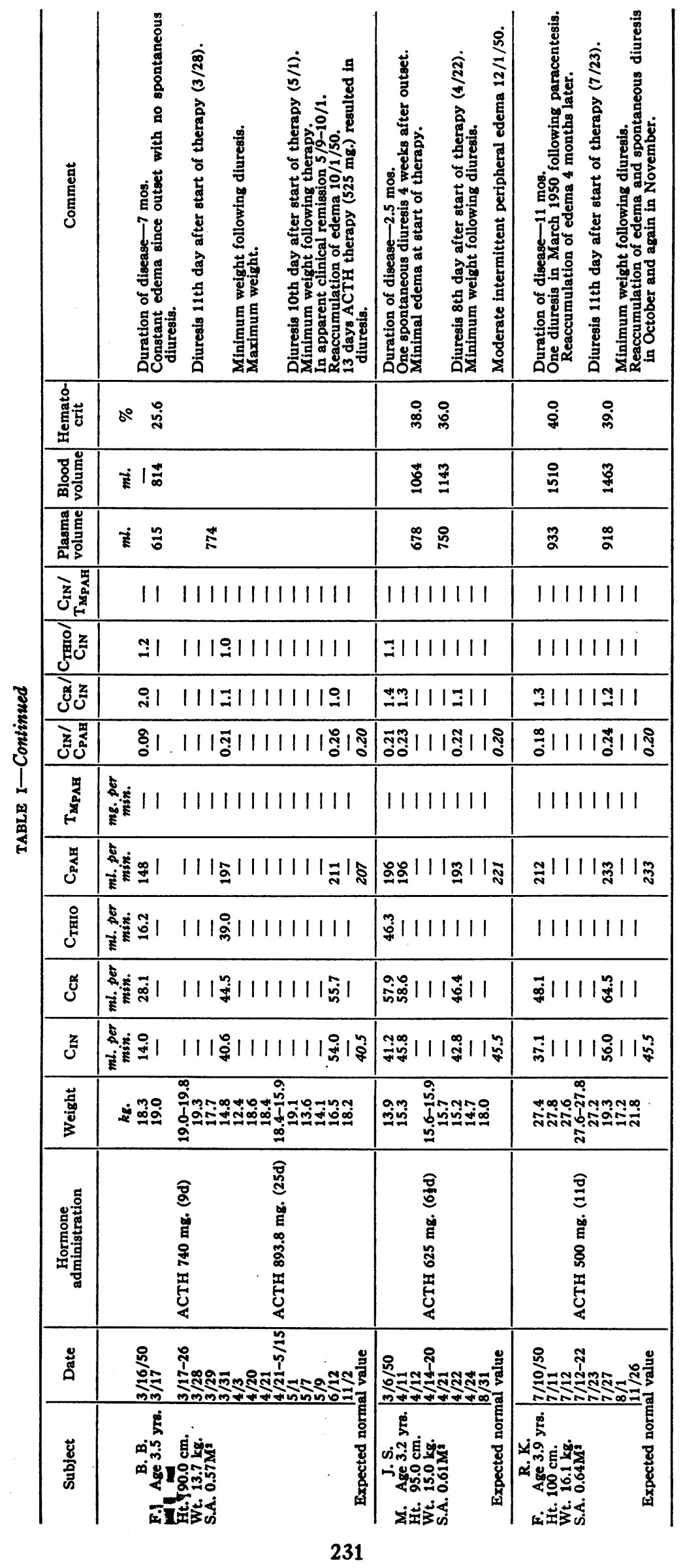




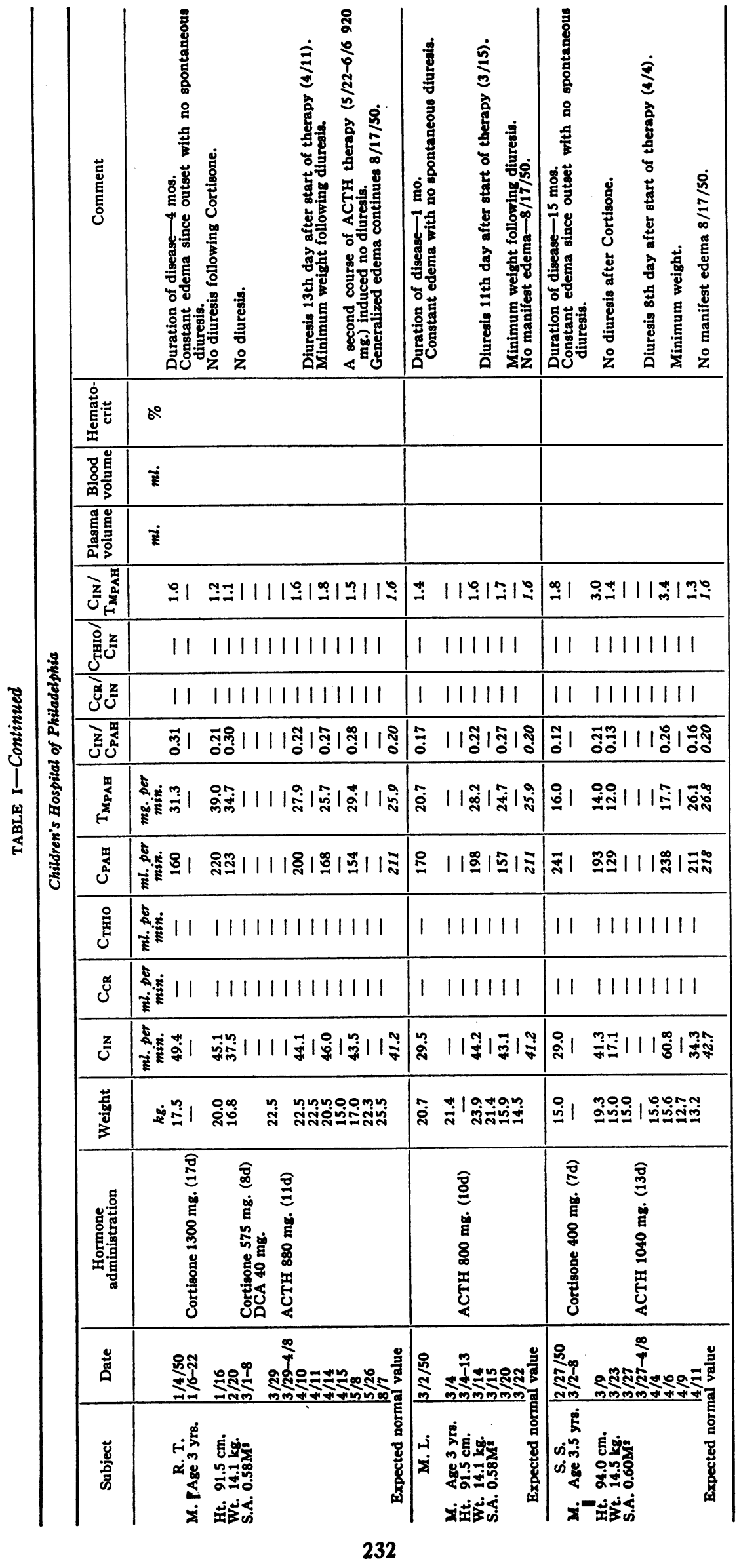


in the $\mathrm{C}_{\mathrm{IN}}: \mathrm{C}_{\mathbf{P A B}}$ ratio are associated with vascular changes or alterations in the permeability of the glomerular membrane cannot be assessed at present.

\section{Maximum tubular excretion of $P A H$}

Increases in $\mathrm{T}_{\mathrm{MPAH}}$ accompanied increases in $\mathrm{C}_{\mathrm{IN}}$ in two children (M. L. and S. S.) in whom it was measured before and during diuresis. The changes in $T_{M_{P A H}}$ were less than those in $\mathrm{C}_{\mathrm{IN}}$ so that the $\mathrm{C}_{\mathrm{IN}}: \mathrm{T}_{\mathrm{MPAH}_{\mathrm{PA}}}$ ratios increased from initially low values before to higher values. In the remaining child in whom repeated measurements of $T_{\text {MPAB }}$ were made, no change in $\mathrm{C}_{\mathrm{IN}}$ was observed and the changes in $\mathrm{T}_{\mathbf{M A B}}$ were irregular.

\section{Plasma and blood volume}

Increases in plasma volume during or after diuresis were observed in four out of five children in whom such observations were made. The changes in I. C., K. N., B. B., and J. S. were $29,17,26$, and $11 \%$ respectively, above the control values. Corresponding increases in blood volume in I. C., K. N., and J. S. were observed but the changes were proportionately less because of decreases in hematocrit values. Failure to observe an increase in plasma volume in $\mathrm{R}$. K. may possibly be explained again by a failure to make the measurement at the proper time.

\section{DISCUSSION}

Prompt increases above initially reduced rates of glomerular filtration are commonly seen during the early stages of acute nephritis in children. On the other hand, reduced clearances in children with the nephrotic syndrome of several months' duration have been interpreted as indicating a less reversible process. The rapid increases in glomerular filtration rate reported here in children who had reduced kidney function and who were given ACTH demonstrate, therefore, a potentiality for improvement in function beyond that commonly considered possible in children with the nephrotic syndrome.

There is no evidence and it is not implied that these results are peculiar to diureses induced by ACTH. Although the magnitude of the changes was somewhat greater than those previously reported with other agents $(1,4,19)$, it is entirely possible and probable that quantitatively similar changes may accompany spontaneous or induced diureses.

The results described have no bearing on the question of whether pituitary or adrenal cortical hormones have any direct relationship to the nephrotic syndrome. They do indicate that ACTH administration may induce repeated diureses at predictable times permitting serial measurements of changes which may accompany and be involved in the mechanism of diuresis. Thus large increases in glomerular filtration rate and significant increases in plasma volume were observed during diureses in these children. These observations lend support to the concept (20) that increases in plasma volume and in glomerular filtration rate accompany and may be involved in the mechanism of diuresis in children with the nephrotic syndrome.

\section{SUM MARY}

Profuse, sustained diureses occurring at predictable times in a high percentage of trials during or following administration of ACTH to children with the nephrotic syndrome permitted observations on changes which may accompany and be involved in the mechanism of diuresis. Serial measurements of discrete kidney functions and plasma volume are reported before, during and after 13 such diureses in eight children. The results indicate:

1. In five children with initially reduced rates of glomerular filtration, increases in inulin clearances ranging from 50 to $256 \%$ above control values were observed during or following diureses on five out of six occasions. In three observations on three children with rates of glomerular filtration initially within the normal range, an increase of $54 \%$ was observed in one. Thus in nine observations where inulin clearances were measured before and after the outset of diuresis, significant increases were observed in six.

2. Daily 24-hour creatinine clearances, measured in one of the three instances in which no marked increase in inulin clearance was observed after diuresis, suggest that glomerular filtration rate did increase during diuresis. In addition, the 24-hour clearances suggest that a marked increase in glomerular filtration rate during diuresis may be followed by a decrease from the maximum 
value, but with subsequent stabilization at a value slightly or markedly above the control. Repeated responses in children with reduced function may then be associated with a progressive increase to normal or even "supernormal" values.

3. A consistent decrease in the endogenous creatinine: inulin clearance ratio was observed as glomerular filtration rate increased. However, clearances of thiosulfate and inulin showed reasonably good agreement at both high and low rates of glomerular filtration.

4. Clearances and maximum tubular excretion of $\mathrm{p}$-aminohippurate increased during diuresis but proportionately less than inulin clearances. Consequently, increases in the $\mathrm{C}_{\mathrm{IN}}: \mathrm{C}_{\mathrm{PAB}}$ and the $\mathrm{C}_{\mathrm{IN}}: \mathrm{T}_{\text {MPAB }}$ ratios were observed as rates of glomerular filtration increased.

5. In four of five observations on five children, increases in plasma volume ( $\mathrm{T}-1824)$ ranging from 11 to $29 \%$ above control values were observed during diureses.

\section{CONCLUSIONS}

1. Diureses occurring during or following administration of ACTH to children with the nephrotic syndrome are usually associated with marked improvement in kidney function. Repeated diureses in children with initially reduced function may be associated with progressive increases in rates of glomerular filtration to normal values. These observations demonstrate a potentiality for improvement in function beyond that commonly considered possible in the nephrotic syndrome of many months' duration. It is believed that these changes are not peculiar to diureses associated with ACTH administration but may accompany spontaneous or other types of induced diureses.

2. The changes observed in plasma volume and glomerular filtration rate support the concept that increases in plasma volume and glomerular filtration rate are associated with the mechanism of diuresis in children with the nephrotic syndrome.

\section{ACKNOWLEDGMENTS}

We are indebted to Flora Hurwitz, R.N., Marie Ragni, B.A., Jean Tracy, R.N., and Josephine Codis, R. N., for nursing and technical assistance.

\section{REFERENCES}

1. Luetscher, J. A., Jr., Hall, A. D., and Kremer, V. L., Treatment of nephrosis with concentrated human serum albumin. II. Effects on renal function and on excretion of water and some electrolytes. J. Clin. Invest., 1950, 29, 896.

2. Rosenblum, A. H., Lander, H. B., and Fisher, R. M., Measles in the nephrotic syndrome. J. Pediat., 1949, 35, 574.

3. Fox, C. L., Jr., and McCune, D. J., Electrolyte changes in nephrosis. Occurrence of diuresis following administration of sodium and potassium salts. Am. J. M. Sc., 1948, 216, 1.

4. Chasis, H., Goldring, W., and Baldwin, D. S., Effect of febrile plasma, typhoid vaccine, and nitrogen mustard on renal manifestations of human glomerulonephritis. Proc. Soc. Exper. Biol. \& Med., 1949, 71, 565.

5. Farnsworth, E. B., Metabolic changes associated with administration of adrenocorticotropin in the nephrotic syndrome. Proc. Soc. Exper. Biol. \& Med., 1950, 74, 60.

6. Rapoport, M., Michie, A., Barbero, G., Barnett, H. L., Forman, C. W., McNamara, H., and McCrory, W. W., The effect of adrenocorticotrophic hormone on children with the nephrotic syndrome. I. Clinical observations. In preparation.

7. McNamara, H., Barnett, H. L., Forman, C. W., McCrory, W. W., and Lauson, H. D., The effect of ACTH on children with the nephrotic syndrome. III. Observations on distribution and excretion of water, electrolytes, and nitrogen. In preparation.

8. Barnett, H. L., Hare, K., McNamara, H., and Hare, R., Measurement of glomerular filtration rate in premature infants. J. Clin. Invest., 1948, 27, 691.

9. Hare, R. S., Endogenous creatinine in serum and urine. Proc. Soc. Exper. Biol. \& Med., 1950, 74, 148.

10. Newman, E. V., Gilman, A., and Philips, F. S., The renal clearance of thiosulfate in man. Bull. Johns Hopkins Hosp., 1946, 79, 229.

11. Chinard, F. P., and Eder, H. A., The determination of the concentration of the dye T-1824 in normal and lipemic plasmas. J. Exper. Med., 1948, 87, 473.

12. Smith, C. H., A method for determining the sedimentation rate and red cell volume in infants and children with the use of capillary blood. Am. J. M. Sc., 1936, 192, 73.

13. Woodbury, R. M., Statures and weights of children under six years of age. U. S. Labor Dept. Children's Bureau Publication, No. 87, 1922.

14. DuBois, E. F., Basal Metabolism in Health and Disease. Lea \& Febiger, Philadelphia, 3rd edition, 1936, p. 135.

15. Smith, H. W., Kidney: Structure and Function in Health and Disease. Oxford University Press, New York. In press. 
16. Barnett, H. L., Kidney function in young infants. Pediatrics, 1950, 5, 171.

17. Hare, K., Goldstein, H., Barnett, H. L., McNamara, H., and Hare, R. S., Renal excretion of creatinine in man. Federation Proc., 1949, 8, 67.

18. Sirota, J. H., Baldwin, D. S., and Villarreal, H., Diurnal variations of renal function in man. J. Clin. Invest., 1950, 29, 187.

19. Cargill, W. H., Effect of the intravenous administra- tion of human serum albumin on renal function. Proc. Soc. Exper. Biol. \& Med., 1948, 68, 189.

20. Eder, H. A., Chinard, F. P., Greif, R. L., Cotzias, G. C., Hiller, A., Van Slyke, D. D., and Lauson, H. D., A study of the changes in plasma volume, renal function, and water and salt balance induced by repeated administration of human plasma albumin to patients with the nephrotic syndrome. J. Clin. Invest., 1948, 27, 532. 